\title{
А.М. Баранов
}

\section{О ЦЕЛИ ДОКАЗЫВАНИЯ В СОВРЕМЕННОМ УГОЛОВНОМ ПРОЦЕССЕ РОССИИ}

\begin{abstract}
Статья посвящена проблеме соотношения цели доказывания назначению уголовного процесса. Отмечается наличие противоречия в этом вопросе как в действующем законодательстве, так и в теории современного уголовно-процессуального права России. Делается вывод о том, что определение цели доказывания в науке зависит от того, какая будет выбрана методология исследования, приверженцем какого подхода борьбы с преступностью будет являться исследователь и, наконец, сторонником какого типа уголовного процесса он будет являться.
\end{abstract}

Ключевые слова: цүель доказывания, цуель уголовного процеесса, истина.

Вопрос об истине как цели доказывания в уголовном судопроизводстве, казалось бы давно разрешенный в теории, вновь стал предметом острых дискуссий как среди ученых науки уголовного процесса, так и руководителей самого высокого уровня органов предварительного следствия, прокуратуры и суда.

Началом дискуссии стало утверждение руководителя Следственного комитета России А.И. Бастрыкина, что «...цель уголовного судопроизводства... сформулирована в статье 6 УПК. Эта цель может быть достигнута только тогда, когда правовая оценка содеянного основывается на истинных данных о событии преступления и когда судьба человека не зависит от красноречия сторон. Это невозможно без выяснения фактических обстоятельств уголовного дела такими, какими они были в действительности, то есть установления по делу объективной истины» [1, с. 16].

По прошествии нескольких месяцев 15 февраля 2018 г. на расширенном заседании коллегии Генпрокуратуры Генеральный прокурор Российской Федерации Юрий Чайка выразил мнение, что в работе российских следователей за последние десятилетия произошла деградация, что до 70 \% дел в суде рассматриваются в особом порядке. Суд не исследует доказательства, не вызывает и не допрашивает свидетелей $[2,3]$.

Что же в действительности является целью уголовного процесса? Является ли объективная (материальная) истина целью доказывания, а само доказывание целью уголовного процесса?

Для того чтобы ответить на этот вопрос, попробуем проследить историю самого вопроса.

Если обратиться к научным трудам дореволюционного периода, то обнаруживаем, что целью уголовного процесса, по мнению большинства ученых, являлось доказывание. М.В. Духовской высказывался кратко и категорично: «Вся деятельность процесса сводится, в сущности, к собиранию доказательств и пользованию ими» [4, с. 197]. «Задача уголовного суда - есть открытие в каждом деле безусловной истины», - писал В.К. Случевский [5, с. 69]. Справедливость требует отметить, что российские ученые, определяя целью уголовного процесса доказывание, повторяли идею, ранее высказанную английским ученым И. Бентамом. Его авторству приписывается фраза: «Искусство судопроизводства есть не что иное, как искусство пользоваться доказательствами».

Для дореволюционных авторов типично выдвижение концепции «уголовно-судебной вероятности» [6, c. 172-180; 7, с. 182], «судебной истины», они считали, что «...задачей суда должно быть не стремление к отысканию безусловной материальной истины, а стремление к истине юридической» [8, с. 93; 9, с. 303].

Такой подход российских, да и не только, юристов того времени был обусловлен существовавшим мировоззрением и методологией науки и познания окружающего мира. Во второй половине XIX в. произошло мощное развитие всех наук: философии, логики, математики физики, химии, - что повлекло за собой развитие транспорта, промышленности, медицины. Всего за половину столетия с середины XIX до начала XX в. философия пройдет путь от агностицизма (непознаваемость мира) Д. Юма, философии И. Канта (познания мира на уровне субъективных переживаний), диалектики Гегеля до диалектического материализма К. Маркса, Ф. Энгельса, провозгласивших взаимосвязь теории и практики и возможность достижения материальной истины [10, с. 1-4; 11, с. 269-317; 12].

Марксистское учение о материальной (объективной) истине в начале XX в. еще не стало неотъемлемой составляющей мировоззрения российских юристов, это произойдет позже. Итак, на рубеже XX в. наука уголовного процесса исходила из следующей доктрины: цель процесса - доказывание, а цель доказывания установление юридической истины. Пометим себе, что ученые той поры никак не связывали этот вопрос с учением о типах уголовного процесса.

В советский период марксистское учение о диалектическом материализме и объективной истине станет методологической основой всей науки, и теория права не будет исключением. К 60-м годам XX в. будет разработана концепция материальной (объективной) истины в уголовном процессе. В ней обосновывалось, что только достоверное знание, имеющее характер абсолютной истины в отношении искомых фактов, может служить основой для принятия решения по делу в деятельности органов расследования и суда $[13,14]$.

На основе концепции объективной истины в уголовном процессе и было построено законодательство советского периода. В ст. 2 Основ уголовного судопроизводства Союза ССР и союзных республик от 25.12.1958 и ст. 2 Уголовно-процессуального кодекса РСФСР от 27.10.1960 задачами советского уголовного судопроизводства являлись быстрое и полное раскрытие преступлений, изобличение виновных и обеспечение правильного применения закона с тем, чтобы каждый совершивший преступление был подвергнут спра- 
ведливому наказанию, и ни один невиновный не был привлечен к уголовной ответственности и осужден.

В теории советского уголовного процесса не проводилось различия между целями и задачами [15, c. 42-43]. Цель доказывания УПК РСФСР не закреплял. Большинство ученых выводило цель доказывания - установление истины - из положений ч. 1 ст. 69 УПК РСФСР. Цель - установление объективной истины - в равной мере относилась к стадиям предварительного расследования и судебного разбирательства.

Надо отдать должное ученым и законодателю того времени, с какой последовательностью и логикой были созданы теория и закон, а потом и воплощена в практическую деятельность идея истины в уголовном судопроизводстве. Последовательно, от методологии диалектического материализма к правовой теории доказывания материальной (объективной) истины как цели уголовного процесса, посредством закрепления в нормах УПК РСФСР, была установлена обязанность всестороннего, полного раскрытия преступлений как для органов расследования, так и для суда. Такой порядок производства по уголовным делам укладывался в представление юристов о смешанном типе уголовного процесса.

Вернемся к сегодняшнему дню. В результате распада Советского Союза в 1991 г. и произошедших политической, экономической и судебной реформ все смешалось в данном вопросе и в уголовной политике, и в теории, и в законодательстве.

Если не заострять внимание на различие терминов «цель», «задачи» и «назначение», то в ст. 6 УПК России закреплено, что уголовное судопроизводство предназначено для защиты прав лиц и организаций, потерпевших от преступлений, а также защиты личности от незаконного и необоснованного обвинения, осуждения, ограничения ее прав и свобод.

Обратим внимание - ни слова о государстве. Налицо провозглашение доктрины «охранительного» типа уголовного процесса, при котором права личности и соблюдение должной правовой процедуры важнее борьбы с преступностью. Таким образом, законодатель в 2001 г. официально закрепил доктринальное изменение цели уголовного судопроизводства в Российской Федерации, которое было провозглашено с началом судебной реформы в 1991 г. Как следствие, в теории уголовного процесса были озвучены новые представления о цели уголовного процесса и цели доказывания.

Большинство авторов поддержало законодателя в том, что «цель судопроизводства состоит в защите прав и законных интересов как лиц и организаций, потерпевших от преступлений, так и лиц, незаконно и необоснованно обвиненных или осужденных за совершение преступления, либо незаконно ограниченных в их правах и свободах» [16].

Как всегда, оригинально по стилю выражения, профессор С.А. Александров видит цель уголовного судопроизводства «...в принятии судом юридически значимого решения. Какого? А не все ли равно какого (в смысле оправдания или обвинения), важнее поставить точку в деле, разрешить дело: правосудие свершилось - да здравствует правосудие! Надо избавляться от иллюзий, что уголовная юстиция, оснащенная уго- ловным, уголовно-процессуальным законодательством главным образом (если не исключительно), борется, противодействует, противостоит преступности» [17]. Уголовный процесс, предназначен для регулирования общественных отношений, возникающих в связи с преступлением, между государством и личностью.

Предпринята попытка объединить рассмотренные выше два подхода. Согласно этой позиции, собственным назначением уголовного судопроизводства является защита личности, общества и государства от общественно опасных деяний, охрана прав и свобод личности; социальное назначение уголовно-процессуального права заключается в способности выступать инструментом разрешения правовых конфликтов [18, с. 16, 18].

Критически оценивая содержание ст. 6 УПК РФ, А.С. Барабаш пишет: «Пригодны ли подобным образом сформулированные цели для реализации в деятельности? Нет. Они слишком общи и неконкретны... То, что подлежит доказыванию, по крайней мере, является целью доказывания, а так как доказывание - стержень уголовно-процессуальной деятельности, то и целью уголовного процесса» [19, с. 122]. Тем самым автор призывает вернуться к доктрине соотношения цели процесса и цели доказывания, отстаиваемую российскими учеными более века тому назад. Такого же взгляда придерживается профессор Ю.В. Деришев, полагающий, что целью доказывания является юридическая (формальная) истина [20, с. 104].

Итак, в определении цели уголовного процесса у современных авторов мы обнаруживаем как минимум три подхода. Как следствие этого, нет единства и в определении цели доказывания.

В ст. 85 УПК РФ «Доказывание» законодатель закрепил, что «доказывание состоит в собирании, проверке и оценке доказательств в целях установления обстоятельств, предусмотренных ст. 73 настоящего Кодекса».

Современные авторы стали рассматривать цель доказывания как двуединую - это установление обстоятельств, подлежащих доказыванию, и достижение истины [21, с. 13-14]. Однако некоторые авторы продолжают придерживаться позиции, что целью доказывания должно быть именно установление объективной (материальной) истины. Наиболее последовательно эту идею в своих работах выражает М.К. Свиридов, который считает, что «истина в уголовном процессе необходима, без ее установления приговор лишается качества правосудности. И необходима только объективная (материальная) истина, как адекватно и полно отражающая имевшие в реальности действия подсудимого, за совершение которых он несет ответственность» [22, c. 102]. Об этом же М.К. Свиридов пишет и в других работах [23, с. 5-6; 24, с. 147].

Вместе с тем в последнее время в научных публикациях наблюдается попытка вопрос о том, какая истина, объективная или юридическая, является целью доказывания, вообще оставить без ответа.

Что препятствует современным ученым четко определиться в цели уголовного процесса и цели доказывания? Существенное влияние на это оказывает изменившееся мировоззрение общества, которое про- 
изошло в результате развития научных взглядов на цели и назначение права в целом, в подходах государства в борьбе с преступностью, а также в методологии науки в вопросе о познаваемости мира.

В современной теории российского права общепринято, что главная цель права - упорядочение, организация общественных отношений. Право выполняет регулятивную, охранительную, гуманистическую, идеологическую, воспитательную функции [25, с. 38]. Следовательно, цель уголовно-процессуального права - регулирование отношений, возникающих в связи с уголовным преступлением.

Обращаясь к достижениям науки криминологии, обнаруживаем, что господствующими выступают две теории по борьбе государства с преступностью:

1) теория соблюдения должной правовой процедуры в целях обеспечения гарантии прав граждан, с одной стороны, и борьбы с возрастающей преступностью - с другой;

2) доктрина контроля над преступностью для обеспечения порядка в государстве, провозглашенная Г. Пэккером [26].

Сущность двух принципиально различных теорий обеспечения законности в уголовном судопроизводстве заключается в следующем. Уголовный процесс, построенный на принципе соблюдения должной правовой процедуры, должен быть подчинен такому контролю, который в максимальной степени в состоянии оградить личность от уголовного преследования со стороны государства в лице его специальных органов. Исходя из этой основной идеи, выводятся все остальные либерально-демократические требования к уголовному процессу, а сам процесс построен по состязательной модели.

Доктрина контроля над преступностью построена на примате интересов государства как единого целого, ограждения его от угрозы нарушения этих интересов со стороны граждан. Согласно указанной теории, из уголовного судопроизводства должны быть исключены все формализмы, мешающие борьбе с преступностью. В построении уголовного процесса, особенно досудебной его части, доминируют розыскные начала, сам процесс характеризуется как смешанный.

Различия между розыскным и состязательным типом процессов вытекают из неодинаковости порядка производства и организационного построения органов, осуществляющих досудебное производство, и суда. Указанные различия фундаментальны, они возникали и формировались во всех странах в разное время и под воздействием разных причин. Это очень большая самостоятельная тема, требующая специального исследования. Обозначим отличие двух типов процесса тезисно и обобщенно. Различие заключалось в четком отделении досудебного и судебного производств, постепенном исключении участия суда (судей) в предварительном сборе доказательств. Фактически история в несколько иной форме вернулась на круги своя к судебному порядку производства частно-искового (обвинительного) процесса. Суд перестал быть связанным со сбором доказательств, осуществляемым стороной обвинения. Как следствие, выводы обвинительной власти, полученные в досудебном производстве, потеряли роль обязательных для суда. Именно это позволило суду занимать нейтральное положение в споре сторон при сборе и оценке доказательств в судебном заседании.

По этой причине современное судейское сообщество категорически против восстановления доктрины объективной истины, поскольку считает (и не без оснований), что с восстановлением такой обязанности у суда судьям фактически придется устранять недостатки в доказывании органов расследования и прокурора.

В разрешении вопроса, что же является целью доказывания, нельзя игнорировать то обстоятельство, что методология диалектического материализма и марксистское учение об объективной истине в современном мире уже не являются господствующей теорией.

В середине XX в. формируется неклассическая парадигма, в рамках которой понятие «истина» определялось через важность и всеобщность знания, а не его соответствие действительности. Неклассическая парадигма формируется на базе открытий, сделанных в различных областях познания: концепции парадигм Т. Куна (теория научных революций), «анархистской теории познания» (релятивистская концепция) П. Фейерабенда, доктрине логического атомизма, представляющей собой проекцию структуры знания на структуру мира Л. Витгенштейна, философской герменевтике Х.-Г. Гадамера (гуманитарное познание), кризиса в физике и создания теории относительности А. Энштейна (строгого логического пути от эмпирии к теории не существует; необходимо дедуктивно вывести более частные утверждения, которые согласуются с имеющимися эмпирическими данными), социального конструкционизма, социологической теории познания П. Бергера и Т. Лукмана (социальный конструкт и лежащая в его основе идея остаются изобретением или искусственно созданным культурным артефактом, принадлежащим определённой культуре или сообществу; человек избирателен по отношению к социальным конструктам, принимая одни и отвергая другие).

Возникают теории когерентной истины: отказ от соотнесения знания с действительностью и признание в качестве определяющего для истины такого внутреннего свойства самого знания, как его непротиворечивость, самосогласованность (М. Шлик, О. Нейрат); конвенционалистской истины: истина - это результат соглашения, конвенции ученых относительно того, что считать истинным (А. Пуанкаре, Р. Карнап); прагматической истины - истина рассматривалась как знание полезное, приносящее успех на практике (Ч. Пирс, У. Джемс, Дж. Дьюи).

В результате формируется вывод, что гуманитарные знания всегда относительны, многозначны, вероятностны и непроверяемы. Категория «истина» является относительной, исторически изменчивой. Нет и не должно быть истины как строгого соответствия действительности.

Потребность современного осмысления учения об истине в уголовном процессе подтвердила состоявшаяся в Северо-Западном филиале Российского государственного университета правосудия г. СанктПетербург 16-17 марта 2018 г. Всероссийская научно- 
практическая конференция «Юридическая истина в уголовном праве и процессе».

Выступления участников конференции еще больше обозначили актуальность вопроса, является ли истина целью уголовно-процессуального доказывания. Были высказаны совершенно различные взгляды по данной проблеме, в том числе: о необходимости разработки в уголовно-процессуальном праве самостоятельной методологии познания (Л.А. Воскобитова); об отказе от теории истины в уголовном процессе (А.С. Александров); целью доказывания является установление обстоятельств, подлежащих доказыванию (А.А. Тарасов).
Если уважаемый читатель в завершении статьи ждет от автора ответа на вопрос, что является целью доказывания, то вынужден его разочаровать. В рамках настоящей публикации это невозможно. Автор и не ставил себе такую задачу. Цель была продемонстрировать, что ответ на данный вопрос в современной юридической науке неоднозначен и зависит как минимум от трех определяющих обстоятельств. Во-первых, от того, какая будет выбрана методология исследования. Во-вторых, приверженцем, какого подхода государства в борьбе с преступностью он выступает. И наконец, сторонником какого типа уголовного процесса он является.

\section{ЛИТЕРАТУРА}

1. Бастрыкин А.И. 300 лет российского следствия // Следствие в России: три века в поисках концепции : материалы Международной научно-практической конференции (Москва, 12 октября 2017 года) / под общ. ред. А.И. Бастрыкина. М. : Московская академия Следственного комитета Российской Федерации, 2017. 311 с.

2. Генпрокурор Юрий Чайка констатировал деградацию российского следствия. URL: http://www.rline.tv/news/2018-02-22genprokuror-yuriy-chayka-konstatiroval-degradatsiyu-rossiyskogo-sledstviya/ (дата обращения: 01.04.2018).

3. Чайка рассказал о деградации в работе российских следователей. URL: https://ria.ru/society/20180221/1515063176.html (дата обращения: 01.04.2018).

4. Духовской М.В. Русский уголовный процесс. М. : Тип. А.П. Поплавского, 1910. 448 с.

5. Случевский В.К. Учебник русского уголовного процесса. Судоустройство - судопроизводство. 4-е изд., доп. и испр. СПб. : Тип. М.М. Стасюлевича, 1913. 684 с.

6. Фойницкий И.Я. Курс уголовного судопроизводства / общ. ред., послесл., прим. А.В. Смирнова. СПб. : Альфа, 1996. Т. 2. 606 с.

7. Познышев С.В. Элементарный учебник русского уголовного процесса. М. : Г.А. Леман, 1913. 337 с.

8. Михайловский И.В. Основные принципы организации уголовного суда. Томск : Паровая типо-лит. П.И. Макушина, 1905.336 с.

9. Розин Н.Н. Уголовное судопроизводство. Пособие к лекциям. 3-е изд., пересмотр. Пг. : Изд. юрид. кн. скл. «Право», 1916. $603 \mathrm{c}$.

10. Маркс К. Сочинения. Т. 3 (1845-1847) / Ин-т марксизма-ленинизма при ЦК КПСС. 2-е изд. М. : Госполитиздат, 1955.630 с.

11. Маркс К. Сочинения. Т. 21 / Ин-т марксизма-ленинизма при ЦК КПСС. 2-е изд. М. : Госполитиздат, 1961.745 с.

12. Кант И. Критика чистого разума. М. : Лань, 2013. 452 с.

13. Строгович М.С. Материальная истина и судебные доказательства в советском уголовном процессе / отв. ред. Б.С. Никифоров. М. : Изд-во АН СССР, 1955. 382 с.

14. Теория доказательств в советском уголовном процессе. 2-е изд. М. : Юрид. лит., 1973. 734 с.

15. Алексеев В.Б., Алексеева Л.Б., Божьев В.П. и др. Курс советского уголовного процесса. Общая часть / под ред. А.Д. Бойкова, И.И. Карпеца. М. : Юрид. лит., 1989. 640 с.

16. Смирнов А.В., Калиновский К.Б. Уголовный процесс. СПб. : Питер, 2005. 272 с. (Серия «Краткий курс») URL: http://kalinovsky-k.narod.ru/p/krat_kurs/1-2.htm. (дата обращения: 05.03.2018).

17. Александров А.С., Александрова И.А. Уголовный Кодекс + Уголовный Процесс = Уголовное право // Актуальные проблемы взаимосвязи уголовного права и уголовного процесса : сб. материалов Всерос. науч.-практич. конф. с международным участием (Уфа, Институт права БашГУ, 31 октября 2016 г.). Уфа : РИЦ БашГУ, 2016. 290 c. URL: http://www.iuaj.net/node/2136 (дата обращения: 05.03.2018).

18. Смирнова И.Г. Социальная ценность Российского уголовного судопроизводства : автореф. дис. ... д-ра юрид. наук. Томск, 2012. $50 \mathrm{c}$.

19. Барабаш А.С. Природа российского уголовного процесса, цели уголовно-процессуальной деятельности и их установление. СПб. : Изд-во Р. Асланова «Юридический центр Пресс», 2005. 257 с.

20. Деришев Ю.В. Доказательства и доказывание // Уголовный процесс : в 2 ч. Ч. 1 : учебник для вузов / под ред. Б. Б. Булатова, А. М. Баранова. 6-е изд., перераб. и доп. М. : Юрайт, 2017. 165 с. Серия: Бакалавр.

21. Галоганов Е.А. Проблемы реализации принципа состязательности в уголовном судопроизводстве Российской Федерации : автореф. дис. .... канд. юрид. наук. М., 2008. 30 с.

22. Свиридов М.К. Задача установления истины и средства ее достижения в уголовном процессе // Вестник Томского государственного университета. Право. 2013. № 2. С. 101-106.

23. Свиридов М.К. Состязательность и установление истины в уголовном судопроизводстве // Правовые проблемы укрепления российской государственности. Ч. 10: Проблемы уголовного процесса в свете нового Уголовно-процессуального кодекса Российской Федерации : сб. ст. / под ред. Ю. К. Якимовича. Томск : Изд-во Том. ун-та, 2002. С. 3-7.

24. Свиридов М.К. Установление судом истины в судебном разбирательстве // Вестник Томского государственного университета. 2011. № 353. С. 142-147.

25. Венгеров А.Б. Теория государства и права: Учебник для юридических вузов. 3-е изд. М. : Юриспруденция, 2000.528 с.

26. Packer H. The Limits of Criminal Sanctions. N. Y., 1968. 375 p.

\section{ON THE PURPOSE OF PROOF IN THE MODERN CRIMINAL PROCEDURE OF RUSSIA}

Ugolovnaya yustitsiya - Russian Journal of Criminal Law, 2018, no. 11, pp. 23-28. DOI 10.17223/23088451/11/5

Aleksandr M. Baranov, Omsk Academy of the Ministry of Internal Affairs of the Russian Federation (Omsk, Russian Federation).

E-mail: baranowam@list.ru 
Keywords: purpose of proof, purpose of criminal procedure, truth.

What is the purpose of proof in the modern criminal procedure? In today's Russia, a dispute arose about truth as the purpose of proof, and the initiative to discuss the problem comes from the leaders of the investigative bodies and the prosecutor's office. To answer this question, it is necessary to trace how scientific views developed on the question of the purpose of the criminal procedure and the purpose of proof in the science of the criminal procedure over the last hundred years.

The works of the pre-revolutionary period show that, in the opinion of the majority of scholars, the purpose of the criminal procedure was proof. Pre-revolutionary authors typically introduced concepts of "criminal-judicial probability", "judicial truth"; they believed that the purpose of proof was the establishment of legal (and not objective) truth.

In the Soviet period, the purpose of criminal proceedings was the demand for a "quick and full disclosure of crimes", and the purpose of proof was objective truth. At the same time, it is necessary to pay tribute to the scholars and the legislator of that time for their consistency and logic in developing the theory and law, and later in putting the idea of truth in criminal proceedings in practical activity. Consistently, from the methodology of dialectical materialism to the legal theory of proof of material (objective) truth as the purpose of the criminal procedure, the obligation of a comprehensive disclosure of crimes both for investigation bodies and for the court was established and fixed in the norms of the RSFSR Code of Criminal Procedure. This order of criminal proceedings fit into the representation of lawyers on the mixed type of the criminal procedure.

Today, scholars attempt to generally leave the question of what truth, objective or legal, is the purpose of proof unanswered in their works. What prevents modern scholars from giving a clear definition of the purpose of the criminal procedure and the purpose of proof? A significant impact on it is made by the change in the world outlook of society, which occurred as a result of the development of scientific views on the aims and purpose of law, in the approaches of the state in the fight against crime, as well as in the methodology of science in the question of the world's cognisability.

Thus, resolving the issue of the purpose of the modern criminal procedure and the purpose of proof is influenced by the choice of a research methodology, by the state conception of combating crime taken as basic, and by the type of the criminal procedure.

\section{References}

1. Bastrykin, A.I. (2017) [300 years of the Russian investigation]. Sledstvie v Rossii: tri veka v poiskakh kontseptsii [Investigation in Russia: three centuries in search of the concept]. Proceedings of the International Conference. Moscow. October 12, 2017. Moscow: Academy of the Investigative Committee of the Russian Federation. (In Russian).

2. Rline.tv. (2018) Genprokuror Yuriy Chayka konstatiroval degradatsiyu rossiyskogo sledstviya [Prosecutor General Yuri Chaika noted the degradation of the Russian investigatio]. [Online] Available from: http://www.rline.tv/news/2018-02-22-genprokuror-yuriychayka-konstatiroval-degradatsiyu-rossiyskogo-sledstviya/. (Accessed: 01.04.2018).

3. Ria.ru. (2018) Chayka rasskazal o degradatsii v rabote rossiyskikh sledovateley [Chaika told about the degradation in the work of Russian investigators]. [Online] Available from: https://ria.ru/society/20180221/1515063176.html. (Accessed: 01.04.2018). 4. Dukhovskoy, M.V. (1910) Russkiy ugolovnyy protsess [Russian criminal procedure]. Moscow: Tip. A.P. Poplavskogo.

5. Sluchevskiy, V.K. (1913) Uchebnik russkogo ugolovnogo protsessa. Sudoustroystvo - sudoproizvodstvo [Textbook of the Russian criminal procedure. Legal structure - legal proceedings]. 4th ed. St. Petersburg: Tip. M.M. Stasyulevicha.

6. Foynitskiy, I.Ya. (1996) Kurs ugolovnogo sudoproizvodstva [A course of criminal proceedings]. Vol. 2. St. Petersburg: Al'fa.

7. Poznyshev, S.V. (1913) Elementarnyy uchebnik russkogo ugolovnogo protsessa [Elementary textbook of the Russian criminal procedure]. Moscow: G.A. Leman.

8. Mikhaylovskiy, I.V. (1905) Osnovnye printsipy organizatsii ugolovnogo suda [Basic principles of the organisation of a criminal trial]. Tomsk: Parovaya tipo-lit. P. I. Makushina.

9. Rozin, N.N. (1916) Ugolovnoe sudoproizvodstvo. Posobie k lektsiyam [Criminal proceedings. A guide to lectures]. 3rd ed. Petrograd: Izd. yurid. kn. skl. "Pravo".

10. Marx, K. (1955) Sochineniya [Works]. Vol. 3. Translated from German. 2nd ed. Moscow: Gospolitizdat.

11. Marx, K. (1961) Sochineniya [Works]. Vol. 21. Translated from German. 2nd ed. Moscow: Gospolitizdat.

12. Kant, I. (2013) Kritika chistogo razuma [Critique of Pure Reason]. Translated from German. Moscow: Lan'.

13. Strogovich, M.S. (1955) Material'naya istina i sudebnye dokazatel'stva v sovetskom ugolovnom protsesse [Material truth and judicial evidence in the Soviet criminal trial]. Moscow: USSR AS.

14. Zhogin, N.V. (ed.) Teoriya dokazatel'stv $v$ sovetskom ugolovnom protsesse [Theory of proof in the Soviet criminal procedure]. 2nd ed. Moscow: Yuridicheskaya literatura.

15. Boykov, A.D. \& Karpets, I.I. (eds) (1989) Kurs sovetskogo ugolovnogo protsessa. Obshchaya chast' [The course of the Soviet criminal procedure. The general part]. Moscow: Yuridicheskaya literatura.

16. Smirnov, A.V. \& Kalinovskiy, K.B. (2005) Ugolovnyy protsess [Criminal procedure]. St. Petersburg: Piter. [Online] Available from: http://kalinovsky-k.narod.ru/p/krat_kurs/1-2.htm. (Accessed: 05.03.2018).

17. Aleksandrov, A.S. \& Aleksandrova, I.A. (2016) [Criminal Code + Criminal procedure = Criminal law]. Aktual'nye problemy vzaimosvyazi ugolovnogo prava i ugolovnogo protsessa [Topical problems of interrelation of criminal law and criminal procedure]. Proceedings of the All-Russian conference with international participation. Ufa, Institute of Law, Bashkir State University. October 31, 2016. Ufa: RIC Bashkir State University. [Online] Available from: http://www.iuaj.net/node/2136. (Accessed: 05.03.2018).

18. Smirnova, I.G. (2012) Sotsial'naya tsennost' Rossiyskogo ugolovnogo sudoproizvodstva [Social value of the Russian criminal proceedings]. Abstract of Law Dr. Diss. Tomsk.

19. Barabash, A.S. (2005) Priroda rossiyskogo ugolovnogo protsessa, tseli ugolovno-protsessual'noy deyatel'nosti i ikh ustanovlenie [The nature of the Russian criminal procedure, the objectives of criminal procedural activity and their establishment]. St. Petersburg: Izdatel'stvo R. Aslanova "Yuridicheskiy tsentr Press".

20. Derishev, Yu.V. (2017) Dokazatel'stva i dokazyvanie [Evidence and proof]. In: Bulatov, B.B. \& Baranov, A. M. (eds) Ugolovnyy protsess. $V 2$ ch. [Criminal Procedure. In 2 parts]. Pt. 1. Moscow: Izdatel'stvo Yurayt.

21. Galoganov, E.A. (2008) Problemy realizatsii printsipa sostyazatel'nosti v ugolovnom sudoproizvodstve Rossiyskoy Federatsii [Problems of the implementation of the adversarial principle in the criminal proceedings of the Russian Federation]. Abstract of Law Cand. Diss. Moscow. 
22. Sviridov, M.K. (2013) The task of ascertaining the truth and the means of its achievement in criminal procedure. Vestnik Tomskogo gosudarstvennogo universiteta. Pravo - Tomsk State University Journal of Law. 2 (8). pp. 101-106. (In Russian).

23. Sviridov, M.K. (2005) Sostyazatel'nost' i ustanovlenie istiny v ugolovnom sudoproizvodstve [Adversariality and the establishment of truth in criminal proceedings]. In: Yakimovich, Yu.K. (ed.) Pravovye problemy ukrepleniya rossiyskoy gosudarstvennosti [Legal problems of strengthening Russian statehood]. Pt. 10. Tomsk: Tomsk State University. pp. 3-7.

24. Sviridov, M.K. (2011) Establishment of the truth in the course of trial. Vestnik Tomskogo gosudarstvennogo universiteta - Tomsk State University Journal. 353. pp. 142-147. (In Russian).

25. Vengerov, A.B. (2000) Teoriya gosudarstva i prava: Uchebnik dlya yuridicheskikh vuzov [Theory of state and law: a textbook for law schools]. 3rd ed. Moscow: Yurisprudentsiya.

26. Packer, H. (1968) The Limits of Criminal Sanctions. N.Y.: Stanford University Press. 